\title{
TDS and pH Analysis for Water Quality Monitoring in Water Hydraulics Food Processor
}

\author{
Ahmad Anas Yusof ${ }^{1 *}$, Syarizal Bakri ${ }^{1}$, Suhaimi Misha ${ }^{1}$ \\ ${ }^{1}$ Faculty of Mechanical Engineering, \\ Universiti Teknikal Malaysia Melaka, HangTuah Jaya, 76100 Durian Tunggal, Melaka, MALAYSIA \\ *Corresponding Author
}

DOI: https://doi.org/10.30880/ijie.2019.11.04.024

Received 7 August 2019; Accepted 22 August 2019; Available online 31 August 2019

\begin{abstract}
This study proposes a low-cost water hydraulics food processor for a traditional cookies production. The hygienic, safe and low maintenance cost characteristics of water should provide interesting viewpoints due to concern over issues in hydraulic fluid contamination, flammability, disposal, and costly maintenance. The objective of this project is to introduce the design and the working principle of the water hydraulics-driven food processor, and to determine production process performances and capabilities. In this paper, results of the corrosion monitoring of the test bed is presented. PLC is used in the testing of the machine, by creating an automatic movement of the cylinders. The Total Dissolved Solids (TDS) and pH analysis of the water hydraulics quality used in the process is discussed.
\end{abstract}

Keywords: Water Hydraulics, TDS, pH, Water Quality, Sustainability

\section{Introduction}

The objective of this project is to develop a food processor using water as the pressure medium and controlled low cost electro-hydraulic components and controllers. Water hydraulics encourages a sustainable approach in power transmission. [1]. Basically, the aim of using water is to transfer the fluid energy, power and the resource sustainably, with environmental friendly impact. The hygienic, safe and low maintenance cost characteristics of water should provide interesting viewpoints due to concern over issues in hydraulic fluid contamination, flammability, disposal, and costly maintenance [2-3]. Currently, water hydraulics offer various hygiene solution in the food processing industry, as demonstrated in the water hydraulics beef cutter, burger production and ice filling machine. Other environmental friendly application also includes the use in underwater application, automotive, sustainable industrial scissor lift and waste packer lorry [4-13]. Thus, the project focuses on the development of a traditional food processor apparatus powered by water hydraulics. The quality of the water used in the power transmission medium is tested for $\mathrm{pH}$ and TDS readings. A test rig consists of two water hydraulics cylinders have been developed for the system and assembled into a robotic manipulator driven by a low-cost water hydraulic system [14]. The cylinders have double acting configuration, with bore size and stroke of $40 \mathrm{~mm}$ and $125 \mathrm{~mm}$ respectively. The test rig is controlled by CP2M OMRON programmable logic controller system, to produce an automatic food processing movement. The system resembles an automated cookies extrusion system, whereby the cookie dough is pressed to form a unique shape for the cookies, as shown in Fig. 1. 


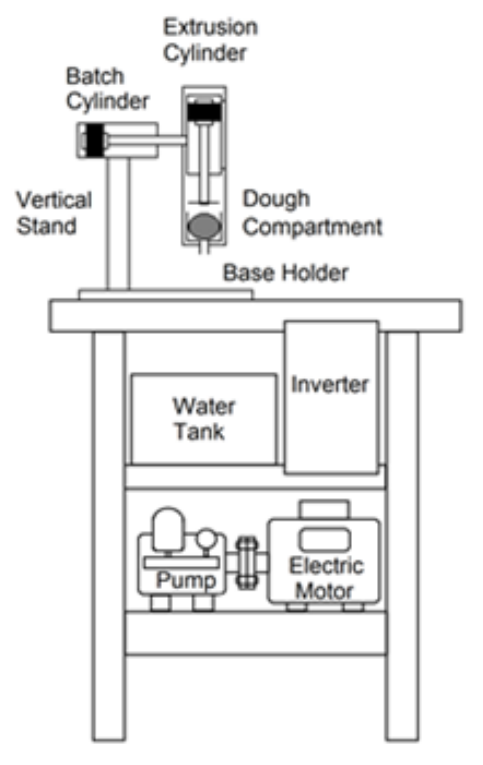

Fig. 1 - Water-powered cookies production system [14].

\section{Literature Review}

\subsection{Advantages and disadvantages of water hydraulic}

One advantage of water hydraulics is that it is suitable for hygiene solution in food processing industry, which can be used to replace bio-oil or oil based hydraulic systems. In comparison to pneumatic system, water hydraulics system has the advantages of much higher efficiency and saving energy costs, lighter weight of devices due to higher power density, and significant advantages of easy to flush and clean according to the requirements and regulations in the food processing industry, [15].

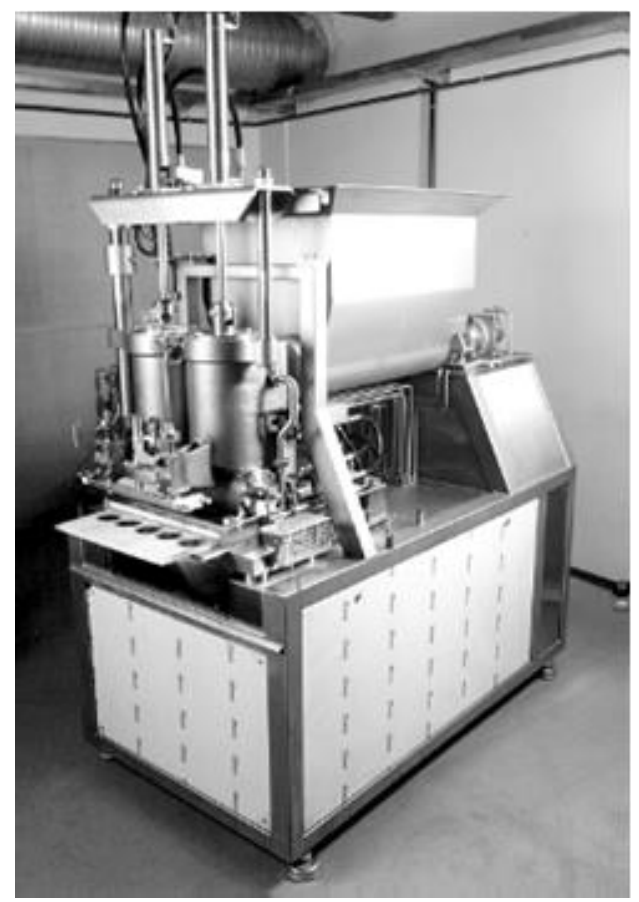

Fig. 2 - Water-powered burger machine [15].

Nowadays, water hydraulics still faces with some main difficulties for widening application. The first challenge is the expensive water hydraulic components capital cost, which is normally more expensive than traditional hydraulic oil. 
However, the low maintenance cost of acquiring and disposing the water can compensate the previous initial cost. The second challenge is that the control performances of water hydraulic systems are affected by nonlinearity due to strong friction and considerable leakage than oil hydraulics. Furthermore, due to its nature, water hydraulics is always measured as having a low energy efficiency, lower than their counterparts. The third challenges involve the corrosion aspects associated with water properties. In water hydraulics system, corrosion depends on the condition of the metal surface, either it is directly in contact with water, or protected with a protective surface films. It also depends on the nature of the environment, with $\mathrm{pH}$ values. In the $\mathrm{pH}$ range of 4-10, corrosion rate is independent of $\mathrm{pH}$, but it increases rapidly when the $\mathrm{pH}$ falls below 4 . The increase in oxygen and water flow rate will also increase the corrosion rate. The increase in oxygen content will increase in oxygen concentration, that usually gives an increase in corrosion rate. The increase in flow rate will increase oxygen access to the surface and removes protective surface films, which will usually increase the possibility of corrosion. However, in some occasions, this will improve access for corrosion-inhibiting reactants. At the same time, generally, low corrosion rates are found with the scale-forming hard waters [16].

\subsection{Total dissolved solids}

Total dissolved solids (TDS) refers to the amount of minerals, metals, organic material and salts that are dissolved in a certain water volume that is expressed in $\mathrm{mg} / \mathrm{L}$. It is directly associated with the quality and purity of water, and very important in water hydraulics system analysis. Total dissolved solids are measured as parts per million (ppm). In general, sea water has a total dissolved solids (TDS) concentration of about $35,000 \mathrm{mg} / 1$. About 78 percent is sodium chloride, 11 percent magnesium chloride, 6 percent magnesium sulfate, 4 percent calcium sulfate, with the remainder primarily potassium sulfate, calcium carbonate, and magnesium bromide, in addition to suspended solids and microbiological organisms. The U.S. Geological Survey classifies water with less than $1000 \mathrm{mg} / 1 \mathrm{TDS}$ as fresh, 1000 to $3000 \mathrm{mg} / \mathrm{l}$ as slightly saline, 3000 to $10,000 \mathrm{mg} / \mathrm{l}$ as moderately saline, 10,000 to $35,000 \mathrm{mg} / 1$ as very saline, and more than $35,000 \mathrm{mg} / 1$ as brine. The total solid content should be less than $500 \mathrm{mg} / \mathrm{l}$, based on the industrial uses of public water supplies and not on public health factors. Higher concentrations cause physiological effects and make drinking water less palatable. Dissolved solids, such as calcium, bicarbonates, magnesium, sodium, sulfates, and chlorides, cause scaling in plumbing above $200 \mathrm{mg} / 1$. The TDS can be reduced by distillation, reverse osmosis, electrodialysis, evaporation, ion exchange, and, in some cases, chemical precipitation.

\subsection{Water pH analysis}

The $\mathrm{pH}$ is a measure of acidity or alkalinity using a scale of 0.0 to 14.0 , with 7.0 being the neutral point, a higher value being alkaline and lower value acidic, as shown in Fig. 3. In the range of $\mathrm{pH} 4$ to $\mathrm{pH} 10$, the corrosion rate of metal is relatively independent of the $\mathrm{pH}$ of the solution. In this $\mathrm{pH}$ range, the corrosion rate is governed largely by the rate at which oxygen reacts with absorbed atomic hydrogen, thereby depolarizing the surface and allowing the reduction reaction to continue. For $\mathrm{pH}$ values below 4.0, metal known as Ferrous Oxide, FeO, is soluble. Thus, the oxide dissolves as it is formed rather than depositing on the metal surface to form a film. In the absence of the protective oxide film, the metal surface is in direct contact with the acid solution, and the corrosion reaction proceeds at a greater rate than it does at higher $\mathrm{pH}$ values.

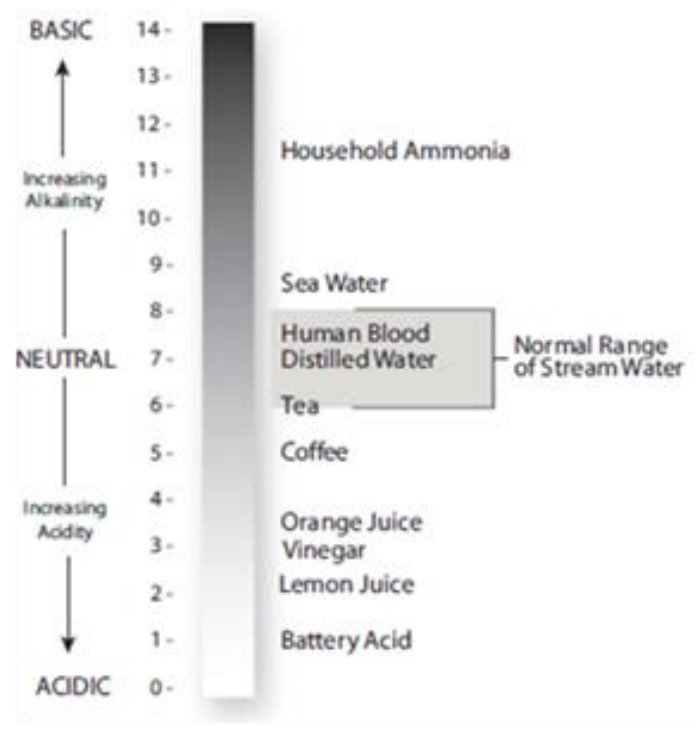

Fig. 3 - pH values. 
In general, hydrogen is produced in acid solutions below a $\mathrm{pH}$ of 4 , indicating that the corrosion rate no longer depends entirely on depolarization by oxygen, but also on a combination of the hydrogen evolution and depolarization. For $\mathrm{pH}$ values above about $\mathrm{pH} \mathrm{10,} \mathrm{the} \mathrm{corrosion} \mathrm{rate} \mathrm{is} \mathrm{observed} \mathrm{to} \mathrm{fall} \mathrm{as} \mathrm{pH}$ is increased. If water $\mathrm{pH}$ drops significantly below 8.5, waterside thinning can occur. The normal manifestation of acidic attack is etching. In areas of higher flow, the surfaces will be smooth. At the same time, any stressed area would be a principal area of attack. Other than physical effects, the bactericidal, virucidal, and cysticidal efficiency of chlorine as a disinfectant also increases with a decrease in $\mathrm{pH}$, as chemical effects. The germicidal activity is greatly reduced at a pH level above 8.0. Corrosion is associated with $\mathrm{pH}$ levels below 6.5 to 7.0 and with carbon dioxide, alkalinity, hardness, and temperature. It is general practice to maintain high temperature water in the alkaline condition, but below very high $\mathrm{pH}$ values to minimize the corrosion of iron and the steels exposed to the high temperature water [17].

\section{Methodology}

The test rig has been setup to work in an automatic mode in producing batches of cookies continuously. The experimentation on the system is conducted by installing an OMRON CPM2A programmable logic controller system, to produce the automatic movement. Fig. 5 shows the PLC unit used in the experimentation [18]. The OMRON CPM2A PLC unit has 20 input and output points, with 12 inputs points and 8 output points. This is enough for the test rig, which has the input sources of 1 start button for automatic movements, 1 stop button and 4 buttons for manual operation. The output sources are 4 solenoid valves and 3 indicator lights. The data obtain are on weekly period from June 2017 to March 2018. The water is tested three 3 times per week and taken before and after the experiment. The water is usually taken from the water tank after every usage. For $\mathrm{pH}$ measurements, data of unfiltered and filtered water is recorded. In this paper, tap water is used for the experiment.

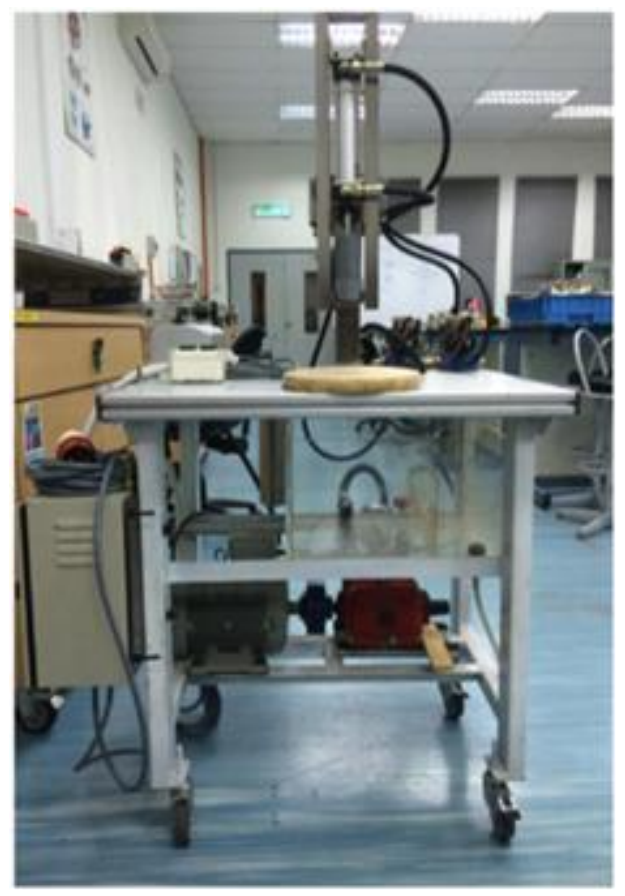

Fig. 4 - Water-powered cookies production system.

\section{Results and Discussions}

\section{1 pH level measurement}

Fig. 6 shows the result obtained for $\mathrm{pH}$ measurement. A control sample is used as a reference, where the $\mathrm{pH}$ reading of 7.66 is recorded on the litmus paper. It is recorded that in between September and November 2017, the test rig shows an increase in $\mathrm{pH}$ values. This is noted when the experiment is conducted without the installation of a highpressure water filter. The filter was later installed in November 2017. In between November and December 2017, the $\mathrm{pH}$ value is noted to be increased. It is possible that the $\mathrm{pH}$ measurement is high due to the prolong unused operation for the food processor. In 2018, the test continues from January till March. It is noted that within that period, the pH values of the water is at a constant $\mathrm{pH}$ 7.8. In general, however, the overall $\mathrm{pH}$ readings are acceptable to reduce 
corrosion effect. As previously mentioned in the previous section, corrosion will aggressively occur below $\mathrm{pH} 4$. In between $\mathrm{pH} 4$ to $\mathrm{pH} 10$, corrosion is independent of $\mathrm{pH}$ value.

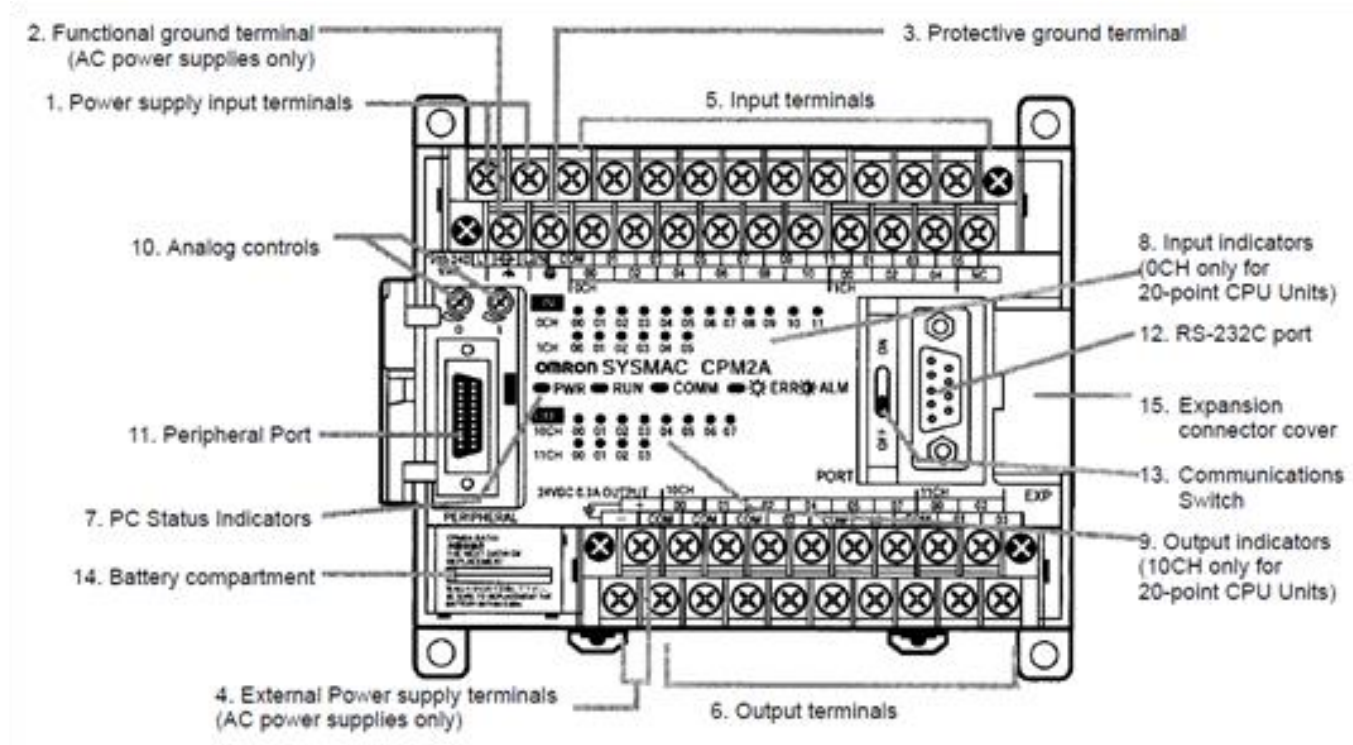

Fig. 5 - PLC unit used in the experimentation.

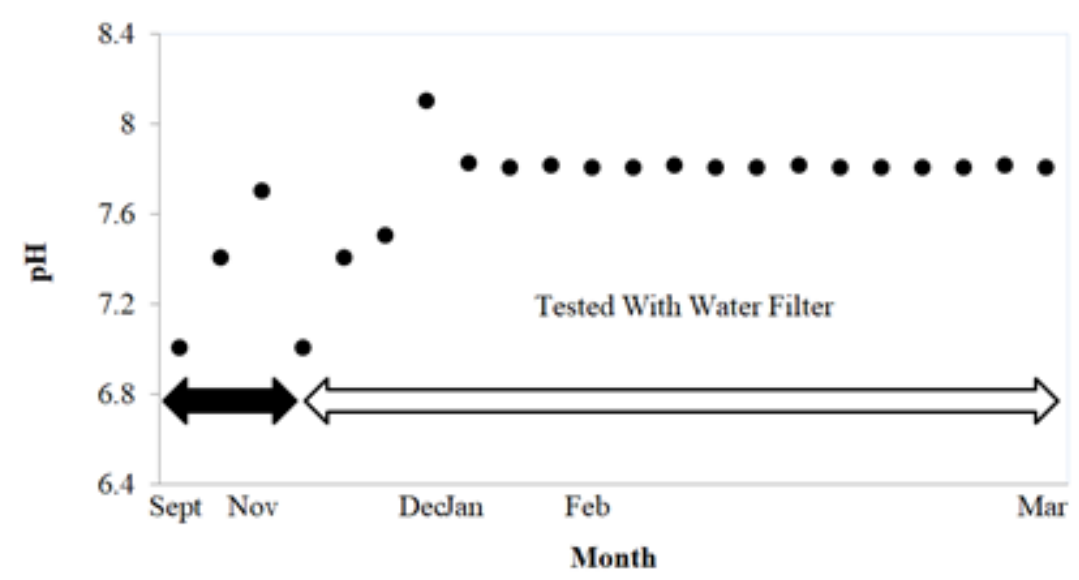

Fig. 6 - Water pH values during the test.

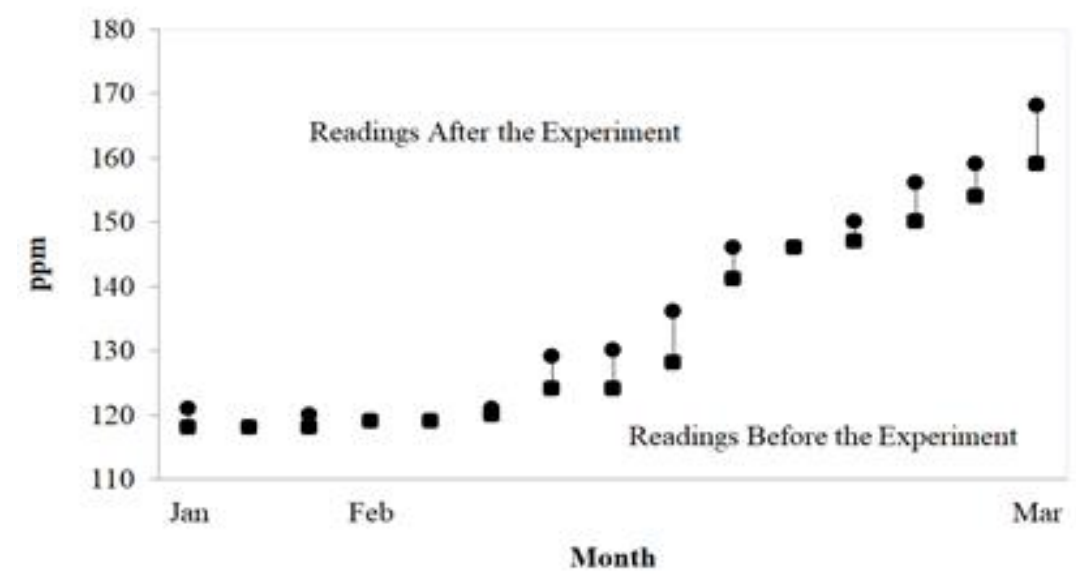

Fig. 7 - TDS readings during the test. 


\subsection{Total dissolved solids (TDS)}

The levels of total dissolved solids affect all that consumes water. Thus, it needs to be measured to ensure the quality of the water and the performance in industrial settings involving pipes, valves and other equipment. This method is used to measure the amount of scale dissolved in the water hydraulics. By knowing the levels of total dissolved solids in the water the quality of the system can be analysed. In this project, scale deposits from hardness build-up is a major factor in causing the food processor to breakdown. It is also one off the factor that affect hygiene issue. Therefore, samples of water are taken each time the food processor is operated. TDS tester is used for the measurement. The results are compared to the control sample, a distilled water. The method used to monitor parts per million level is similar to $\mathrm{pH}$ readings method, that is within the span of five weeks the water is sampled three times a week. Fig. 7 shows the result for TDS readings. For reference purposes the distilled water has been recorded having a TDS reading of $57 \mathrm{ppm}$. The lowest reading for the used water is of $118 \mathrm{ppm}$, which rises to $121 \mathrm{ppm}$ after the operation of the food processor rig. Although filter is used in the system, it is noted than this filter is unable to reduce the TDS readings. The highest TDS reading is of $168 \mathrm{ppm}$ (before) and $159 \mathrm{ppm}$ (after). The increasing trend of TDS is noticeable in the graph.

\section{Conclusion}

The water filtering system for the studied water hydraulics system is becoming weaker over time. It is suggested that the quality of membranes and filters should be monitored, and replacement performed when necessary. In addition to these, TDS can also come from air that contains nitrogen, sulfur, calcium bicarbonate and other kinds of minerals, as well as rocks. Water is capable of picking up copper, lead and other metals as it passes through pipes used to move the cylinder, during the extrusion process. High TDS levels may also indicate the presence of harmful chemicals. It may also indicate the origin of the build-up of scale may originated from the valves and pipes, which is situated after the position of the filter. The increasing trend of TDS is noticeable in the food processor, which suggest for a more thorough study for corrosion rate in the system.

\section{Acknowledgement}

This work was funded by Ministry of Higher Education (MOHE) of Malaysia, under the Fundamental Research Grant Scheme (FRGS). FRGS/1/2016/TK03/FKM-CARE-F00317. The authors wish to thank Mr. Ariff Shazal bin Mohd Salim for his contribution in the simulation and experimentation of the project.

\section{References}

[1] Trostmann, E., Bo, F., Bo, H.O., and Bjarne, H. Tap water as a hydraulic pressure medium. New York: Marcel Dekker, (2001).

[2] Krutz, G.W., and Patrick S. K. C. Water hydraulics - Theory and applications 2004. Workshop on Water Hydraulics, Agricultural Equipment Technology Conference, Louisville, Kentucky. United States, (2004), pp. 133.

[3] Higgins. M. Water hydraulics - The real world. Industrial Robot: An International Journal Volume 23, (1996) pp. 13-18.

[4] Lim, G. H., Chua, P. S. K., and He, Y. B. Modern water hydraulics - The new energy transmission technology in fluid power. Applied Energy. Volume 76, (2003), pp. 239-246.

[5] Backe, W. Water or oil hydraulic in the future. The Sixth Scandinavian International Conference on Fluid Power, SICFP'99, Tampere, Finland (1999) pp. 51-65.

[6] Yusof, A.A., Mat, S., Din, A. T. Promoting sustainability through water hydraulics technology: The effect of water hydraulics in industrial scissor lift. Applied Mechanics and Materials, Volume 315, (2013), pp. 488-492.

[7] Yusof, A.A., Wasbari, F., Ibrahim, M.Q. Research development of energy efficient water hydraulics manipulator for underwater application. Applied Mechanics and Materials, Volume 393, (2013), pp. 723-728.

[8] Pham, P. N., Ito, K., Ikeo, S. Energy saving for water hydraulic pushing cylinder in meat slicer. JFPS International Journal of Fluid Power System, Volume 10, (2017), pp. 24-29.

[9] Zaili, Z.S., Yusof, A.A., Nor, N.F.M., Hanafi, M. H. M., and Ibrahim, M.Q. Characteristics of a reciprocating pump for low-cost sustainable water hydraulic technology demonstrator. Applied Mechanics and Materials, Volume 699, (2015), pp. 736-741.

[10] Sabaruddin, S.A, Yusof, A.A., Saadun, M.N.A. and Ghazali, R. Application of water as pressure medium in hydraulic hybrid system. ARPN Journal of Engineering and Applied Sciences, Volume 12, No. 16, (2017), pp. 4824-4830. 
[11] Yusof, A.A., Wazbari, F. Zakaria, M.S. and Ibrahim, M.Q. Slip flow coefficient analysis in water hydraulics gear pump for environmental friendly application. IOP Conf. Series: Materials Science and Engineering, Volume 50, (2013), pp. 1-8.

[12] Fairfield. C. A. Spatial, temporal, and thermal analysis of a cavitating high-pressure water-jet. Journal of Advanced Research in Fluid Mechanics and Thermal Sciences, Volume 18, (2016), pp. 1-19.

[13] Yusof, A.A., Sabaruddin, S.A., Saadun, M. N. A., Wasbari, F. Volume displacement simulation impact on the water hydraulic hybrid driveline performance. Journal of Advanced Research in Fluid Mechanics and Thermal Science. Volume 43, (2018), pp. 20-36.

[14] Yusof, A.A., Misha, S., Md Isa, M.H., Wasbari, F., Ibrahim, M.Q. and Kasim, M.S. Low cost water hydraulics technology for Malaysian traditional cookies production, Proceedings of the $10^{\text {th }}$ JFPS International Symposium on Fluid Power, Fukuoka, Japan, (2017), pp. 1-8.

[15] Finn C. Trends in design of water hydraulics - Motion control and open-ended solutions. Proceedings of the $6^{\text {th }}$ JFPS International Symposium on Fluid Power, Tsukuba, Japan, (2005), pp 420-430.

[16] Joseph A. S., Nelson L. N., and Franklin J. A. Environmental Engineering. John Wiley \& Sons. (2003).

[17] Vigil, K.M. Clean water: An Introduction to Water Quality and Water Pollution Control. Oregon State University Press, (2003).

[18] SYSMAC CPM2A programmable controller operation manual. OMRON Corporation, (1999). 